\title{
Health and safety challenges associated with immigrant dairy workers
}

\author{
J. Rosecrance, T. Tellechea, L. Menger, D. Gilkey, N. Roman-Muniz \\ College of Veterinary Medicine and Biomedical Sciences, Colorado State University, USA
}

\begin{abstract}
Faced with increasing industrialization, high demands on production, and decreasing domestic participation in the labor force, dairy producers are employing an immigrant workforce to help meet operational demands. There is little data regarding the number of immigrant workers in the dairy industry, but the trend of hiring immigrant workers in some of the world's highest producing countries is increasing. There are many challenges associated with managing immigrant workers includinghow to effectively train this workforce about safe and efficient work methods.

Methods: Ethnographic methods from the anthropology field served as the primary tool to identify barriers and facilitators of safe work practices in large-herd dairy operations in the United States. Following the weeklong emersion by the research anthropologist at a selected dairy, focus groups were organized at three large-herd dairies. All focus group conversations were tape recorded, transcribed and translated into English. The focus group transcripts were coded for specific themes related to issues that participants felt were barriers or facilitators of worker health and safety.

Results: Twenty-two Latino workers 18 to 58 years of age participated in the three focus groups conducted at one Colorado and two South Dakota dairies. Six major themes relating to barriers and facilitators of worker health and safety were identified and included: communication, integration owner and worker cultures, work organization, leadership, support for animal health, and attention to safety culture within the organization.
\end{abstract}

Conclusions: Although not often considered by agricultural engi-

Correspondence: John Rosecrance, 1681 Campus Delivery, Colorado State University. Fort Collins, Colorado, USA 80523. Tel. +001 970.491.1405. E-mail: john.rosecrance@colostate.edu

Key words: immigrant, safety, anthropologic, ergonomics, dairy, workers

Acknowledgments: the present study was supported by the Center for Disease Control (CDC) / National Institute for Occupational Safety and Health (NIOSH) Mountain and Plains Education and Research Center (grant number: 5T420H009229-06) and the High Plains Intermountain Center for Agricultural Health and Safety (grant number: 5U54OH00808509). Its contents are solely the responsibility of the authors and do not necessarily represent the official views of the CDC or NIOSH.

(C) Copyright J. Rosecrance et al., 2013

Licensee PAGEPress, Italy

Journal of Agricultural Engineering 2013; XLIV(s2):e129

doi:10.4081/jae.2013.s2.e129

This article is distributed under the terms of the Creative Commons Attribution Noncommercial License (by-nc 3.0) which permits any noncommercial use, distribution, and reproduction in any medium, provided the original author(s) and source are credited. neers, an anthropological perspective to challenges involving an immigrant workforce may assist with improved work methods and safe work practices. Through this approach, agricultural engineers may better understand the cultural challenges and complexities facing the dairy industry. Successful integration of immigrant workers relies not only on cultural awareness but also the ability to integrate cultural knowledge, beliefs, values, and traditions into management and work practices.

\section{Introduction}

Milk production during the last twenty years in the many parts of the world has increased significantly due to nutritional factors and production methods. During this 20 -year period farms with small herds have all but disappeared being replaced by large ( $>500$ head) and mega-herd ( $>2000$ head) dairies. In many countries, profits in the dairy industry are driven by economies of scale, which have resulted in the transition towards large,and mega-herd milking (Reinemann 2001). Production driven by economies of scale result in a cost advantage with the cost per unit of output (milk) decreasing with increasing scale as fixed costs (e.g., equipment) are spread out over more units of output. In the United States for example, there were 650,000 dairy farms in 1970 as compared to 65,000 in 2009 (down 90\%). During the same period, milk production and herd size increased significantly (NASS, 2010). Similar trends have been documented in other countries. In Australia, the number of dairy farms fell by $67 \%$ over the last three decades from 22,000 in 1980 to just below 7,000 in 2011 (Dairy Australia, 2012). During that same time period average herd size increased $270 \%$ and national milk output more than doubled.

The relatively recent shift towards industrialized production systems in the dairy industry has led to health and safety challenges including greater work demands, task specialization, and higher rates of injuries and illnesses among dairy workers (Douphrate, 2009). Studies now indicate that dairy parlor workers involved with largeherd milking tasks are exposed to extreme shoulder pos tures, high muscle forces, highly repetitive tasks, and insufficient periods of rest (Douphrate, 2011; Douphrate, 2012). Additionally, acute injuries from animal handling (cow kicks, pinned by, and stepped on) have been identified as a significant risk for all dairy workers (Douphrate, 2006). Increased working time, more cows milked per hour, more milking units per parlor, high physical workloads and h ighly repetitive working routines were potential risk factors associated with musculoskeletal symptoms and disorders in dairy studies (Pinzke, 2003; Patil, 2012). The injuries and illnesses experienced by dairy workers may also be related to a mismatch between equipment design (e.g., milking parlor equipment) and worker anthropometrics.

A growing number of large-herd dairy producers are relying on an immigrant workforce to help meet the demands associated with the increased scope and industrialization of the industry (ILO, 2010; Tipples, 2010; Valentine, 2005). The majority of dairy workers in the United States are considered a vulnerable working population with a high proportion (50\% to 84.7\%) from Mexico and Central America 
(Valentine, 2005; Roman-Muniz, 2006). In Italy, a majority of the dairy workers in the highly productive Lombardy region are immigrants from the Punjab region of India (Lum, 2012). The Indian immigrants are essential to Italy's large production of the wellknownParmigianoReggiano and Grana Padanocheeses (Povoledo, 2011). Although the use of immigrant labor provides economic advantages, it may lead to health and safety challenges among works that are often related to cultural differences (Schenker, 2010). There is evidence suggesting that immigrant workers may be at greater risk of occupational injury and illness than domestic workers. The purpose of this study was toidentify the facilitators and barriers of health and safety pract ices among immigrant workers at large-herd dairies in the United States.

\section{Methods}

Ethnographic methods commonly used in the field of anthropology served as the primary tool to identify barriers and facilitators of safe work practices in large-herd dairy operations. Ethnographic research, as a qualitative research method, assumes there is great variability in how people understand and make their worlds meaningful. Researchers may observe and measure worker behavior in a dairy setting, but such behavior does not exist in a social or cultural vacuum. LeCompte(2010) highlighted a primary distinction between ethnography and other investigative methods carried out in the social and behavioral sciences: "...ethnography assumes that researchers must first discover what people actually do and the reasons they give for doing it before trying to interpret their actions. That is why the tools of ethnography are designed for 'discovery' prior to 'testing."

As the growing immigrant labor force brings greater diversity into the dairy industry, it is imperative to take the cultural components of these demographic shifts into account. An ethnographic approach as a mode of discovery aims to tap into the dynamics of the entire dairy worker context, including the workplace, family, and community. This context, which differs across cultures, creates the conditions for the basis of work behaviors. Only by understanding what behavior means from the perspective of the workers will it be possible to design the most effective safety training programs that account for the cultural perceptions. Conversely, traditional safety programs designed by indigenous safety experts and imposed from managers outside of the workers culture often result in little if any transfer of training skills on the job. In the context of the present study, the research team became co-participants in the natural setting of the worker. Through this process, the researcher engages participants in face-to-face interaction; striving for fidelity in the reflection of participant behaviors and perspectives; capturing the local cultural knowledge through 'inductive, interactive and recursive data collection' from multiple sources to understand the human experience within the broader context; and interpreting results through the concept of 'culture as a lens' (Spradley, 1990; DeWalt, 2011).

Consistent with the anthropological approach (LeCompte, 2010), the research team used participant observation, participation, and focus groups in their ethnographic methodology. These methods required the research team to have direct immersion into the context of the dairy workers for an extended period of time. Although several members of the team participated in the participant observation phase at several dairies, the anthropologist was embedded and worked side-by-side with the dairy workers for one-week. This period also included the anthropologist living among the workers at their migrant housing facility. This activity allowed the anthropologist to gain knowledge of the local language and sharing in a wide range of daily routines as full partici- pants in the context of the works lives. This close participation and observation often involves "hanging out" having everyday conversation, which builds trust and reduces the perceived risk of the researcher's presence. An integral part of this process is to normalize the systematic recording of observations in field notes while participating in the worker context (DeWalt, 2011).

Following the weeklong emersion of the anthropologist at the dairy and migrant housing facility, focus groups were organized at the dairy and at two additional dairies in other states. The anthropologist and an additional Spanish-speaking researcher conducted the focus groups. All focus group conversations were tape recorded, transcribed and translated into English at a later date. Data were qualitatively analyzed and grouped into themes for each dairy. The themes for each dairy were then combined to generally represent the three dairies.

\section{Results and discussion}

One focus group was conducted at each of three dairies among a total of 22 workers in the states of Colorado and South Dakota in the United States. The focus group participants ranged in age from 18 to 58 years. All participants were Latino / Latina with two females participating. Focus groups were conducted in Spanish language, the native language of the workers.

Although the general topic of the focus groups was related to safety and health, some diversion about issues indirectly related to safety were allowed. The focus group transcripts were coded for specific themes related to issues that participants felt were pertinent to health and safety. The major themes related to both barriers to and facilitators of worker dairy health and safety are illustrated in Figure 1. Six major themes were identified including communication, the integration cultures represented by the owner and workers, work organization issues, leadership, support for animal health and attention to safety culture within the organization.

The theme of communication was highlighted by issues related to language, specifically the Spanish spoken by the workforce and English by the dairy owner. Often, the head herdsman, which is supervisory position, spoke a combination of English and Spanish and served as the communication link between the owner and workers. Language difficulties were often mentioned as reasons for miscommunications between workers and owners. Good communication was seen as vital for conducting efficient work and safe work methods within and between areas of the dairy. There al so considerable discussion related to how best to communicate safety on the dairy that is discussed in more detail below under the safety culture theme.

The integration of cultures theme was focused on various ways to promote understanding and acceptance of differences between the specific cultural facets of workers and managers/owners. Some workers expressed feelings of bias and alienation because they did not speak English or had an undocumented work status. Culturally appropriate health and safety training was also mentioned as a necessity for worker acceptance.

Work organization developed as a major theme contributing to dairy health and safety and was focused around equipment and work schedules. Workers identified the importance of maintaining and fixing equipment in timely manner as well as having adequate tools for conducting their work as essential parts of working in an efficient and safe manner. Good equipment design in terms of reducing reaching away from the body and bending down were also identified as a possible improvement that would lead to a safer workplace. Workers often discussed the difficulties of working long hours (up to 12 hours 


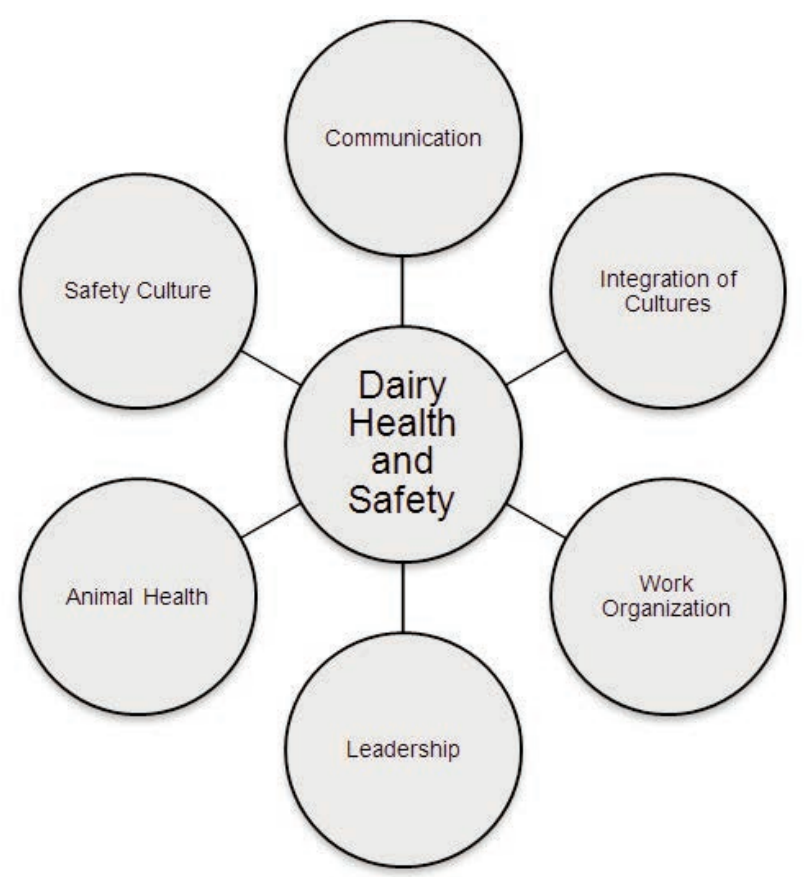

Figure 1. Major themes identified that can be facilitators as well as barriers for worker health and safety.

per day) and working six to seven days per week. Often workers did not get the weekend off when their family was at home. Work breaks (for bathroom and meals) were not often built into the production schedule. There was a general feeling that the lack of adequate tools / equipment as well as stressful work schedules contributed to not only poor safety practices but sacrifices in milk production and quality of work.

The theme of leadership was discussed in regards to leaders that workers could approach with questions regarding work methods as well as safety concerns. Workers expressed a need for leadership presence during all (3) shifts not just during the dayshift. There were also suggestions regarding an "apprenticeship style" training program as a way of developing leaders from the existing workforce. Incorporating health and safety into leadership training was seen as an important aspect of safety.

There was a consensus among all focus group participants regarding the importance of animal health as it related to their daily work tasks as well as their own safety. Animal safety and health was paramount in their work to the degree that it was at times given priority over worker safety. One worker during the focus group explained that "when the owner heard that the cow kicked someone the cow got the most attention." The need for training in animal handling and animal behavior issues was noted, as many workers did not have animal handling experience before coming into the dairy indu stry.

The concept of safety culture was discussed indirectly by each focus group and was perceived as being good to low depending on the dairy organization. There were clear differences in perceptions regarding the level of safety culture by dairy. Some workers indicated that consideration of worker safety was non-existent while others described it as adequate. Nonetheless, most workers felt production was more important to management than worker safety and thought that the safety culture could be improved. Workers indicated that they were given video-based safety training but that it was often not pertinent to dairy work or was not relevant to their specific job tasks. Workers also identified production issues that were barriers to implementing some of the safety ideas described in videos.

Alth ough training was not included as a major theme in the model illustrated above, it was discussed with regards to every theme identified. There was a general consensus that culturally appropriate training that was more relevant to the work and workers could have the greatest impact not only on worker health and safety but also work methods. Many workers expressed frustration with a common organi$\mathrm{z}$ ational culture of learning by trial and error with little or no attention to health and safety. One dairy worker expressed the following statement concerning this general frustration: "In the three jobs I have had in this country nobody has ever explained to me what are the risks of my job and how to prevent them."

\section{Conclusions}

It is clear that the challenges related to improving health, safety, and efficiency on large-herd dairy farms are numerous and significant when immigrant workers are involved. Most of the major themes related to barriers and facilitators to worker health and safety identified are common issues faced by engineers involved in improving health, safety and production efficiency. However, when the majority of the work population involves immigrants, there is a need for focused attention to factors that pertain to the cultural differences between management/owners and workers. The anthropologic methodology incorporated into this study was used to specifically identify (rather than assume) the needs and concerns of a traditionally underserved and vulnerable working population. This study was focused on Latino workers employed in large-herd US dairies. However, countries that experience growth in large-herd milking operations and subsequent growth in immigrant dairy workers likely face similar challenges.

\section{References}

Dairy Australia, 2012. http//dairyaustralia.com.au/ (accessed $25 \mathrm{Jul}$ 2012).

DeWalt KM, DeWalt BR, 2011. Participant observation. Lanham, MA: Altamira Press; 2011.

Douphrate D, Rosecrance JC, Wahl H, 2006. Workers' compensation experience of Colorado agricultural workers, 2000-2004. Am J Ind Med. 49:900-910.

Douphrate D, Nonnenman M, Rosecrance J, 2009. Ergonomics in industrialized dairy operations. J Agromed.14(4):406-412.

Douphrate D. 2011. Musculoskeletal symptoms and physical exposures among U.S. large-herd milking parlour workers.Proceedings of the Irish Meeting on Agricultural Occupational Health and Safety; Aug 22nd-24th; Dublin, Ireland.

Douphrate D, Fethke N, Nonnenmann M, Rosecrance J, Reynolds S, 2012. Full shift arm inclinometry among dairy parlor workers: A feasibility study in a challenging work environment. Appl Ergo. 43(3):604-613.

International Labour Organization(ILO), 2010. MESHA/2010/10. Code of practice on safety and health in agriculture. Geneva, Switzerland: ILO.

LeCompte MD, Schensul JJ, 2010. Design and conducting ethnographic research: An introduction. Lanhan, MD: AltaMira Press.

Lum K, 2012. The quiet Indian revolution in Italy's dairy industry. 
CARIM India. Report number: 2012/08.

National Agricultural Statistics Service (NASS).2010, U.S. and all states data: Dairy.U.S. Department of Agriculture.

Patil A, Rosecrance J, Douphrate D, Gilkey D, 2012.Prevalence of carpal tunnel syndrome among dairy workers. Am J Ind Med. 55(2):127135.

Pinzke S,2003. Changes in working conditions and health among dairy farmers in southern Sweden: A 14-year follow up. Ann Agric Environ Med. 10:185-95.

Povoledo E, 2011. In Italian Heartland, Indians Keep the Cheese Coming. http://www.nytimes.com/2011/09/08/world/europe/08ihtitaly08.html?pagewanted=all\&_r=0(accessed 5 June 2013).

Roman-Muniz IN, Van Metre DC, Garry FB, Reynolds SJ, Wailes WR,
Keefe TJ, 2006. Training methods and association with worker injury on Colorado dairies: A survey. J Agromed.11(2):19-26.

Schenker MB, 2010. A global perspective of migration and occupational health. Am J Ind Med. 2010;53:329-37.

Spradley JP,1980. Participant observation. New York, NY: Holt, Rinehart and Winston.

Tipples R,Trafford S, Callister P, 2010. The factors which have resulted in migrant workers being 'essential' workers on New Zealand dairy farms. Proceedings from Labour, Employment and Work Conference; Nov 30th-Dec 1st; Wellington, New Zealand.

Valentine BE, 2005. United two cultures: Latino immigrants in the Wisconsin dairy industry. Working Paper 121. 